\title{
Effect of pulsation rest phase duration on teat end congestion
}

\author{
J. Upton, ${ }^{* 1}$ J. F. Penry,† M. D. Rasmussen, $\ddagger$ P. D. Thompson, $\S$ and D. J. Reinemann§ \\ *Animal and Grassland Research and Innovation Centre, Teagasc Moorepark, Fermoy, Co. Cork, Ireland \\ †Department of Dairy Science, University of Wisconsin, Madison 53706 \\ $\ddagger$ Aarhus University, Department of Engineering, DK-8000 Aarhus C, Denmark \\ §Biological Systems Engineering Department, University of Wisconsin, Madison 53706
}

\section{ABSTRACT}

The objective of this study was to quantify the effect of d-phase (rest phase) duration of pulsation on the teat canal cross-sectional area during the period of peak milk flow from bovine teats. A secondary objective was to test if the effect of d-phase duration on teat canal cross-sectional area was influenced by milking system vacuum level, milking phase (b-phase) duration, and liner overpressure. During the d-phase of the pulsation cycle, liner compression facilitates venous flow and removal of fluids accumulated in teat-end tissues. It was hypothesized that a short-duration dphase would result in congestion of teat-end tissue and a corresponding reduction in the cross-sectional area of the teat canal. A quarter milking device, designed and built at the Milking Research and Instruction Laboratory at the University of Wisconsin-Madison, was used to implement an experiment to test this hypothesis. Pulsator rate and ratios were adjusted to achieve 7 levels of d-phase duration: 50, 100, 150, 175, 200, 250, and $300 \mathrm{~ms}$. These $7 \mathrm{~d}$-phase durations were applied during one milking session and were repeated for 2 vacuum levels (40 and $50 \mathrm{kPa}$ ), 2 milking phase durations ( 575 and $775 \mathrm{~ms}$ ), and 2 levels of liner overpressure (9.8 and $18 \mathrm{kPa})$. We observed a significant reduction in the estimated cross-sectional area of the teat canal with d-phase durations of 50 and $100 \mathrm{~ms}$ when compared with d-phase durations of $150,175,225,250$, and 300 ms. No significant difference was found in the estimated cross-sectional area of the teat canal for d-phase durations from 150 to $300 \mathrm{~ms}$. No significant interaction was observed between the effect of d-phase and b-phase durations, vacuum level, or liner overpressure.

Key words: milking, pulsation, teat congestion, milk flow

Received September 29, 2015.

Accepted January 12, 2016.

${ }^{1}$ Corresponding author: john.upton@teagasc.ie

\section{INTRODUCTION}

Congestion is the accumulation of blood within the circulatory system - for example, the accumulation of blood in engorged capillaries in the teat end during the b-phase of pulsation. The canals of congested teats have been shown to close more slowly after milking (Neijenhuis et al., 2001), and this delayed closure of the teat canal is thought to result in a longer window of opportunity for mastitis, causing bacteria to pass through the teat canal (Mein et al., 1987; Zecconi et al., 1992; Gleeson et al., 2004). Thicker teats postmilking compared with premilking are associated with higher quarter SCC (Zwertvaegher et al., 2013).

The 4 phases of each pulsation cycle are defined by the International Organization for Standardization (ISO) as a: liner opening; b: liner open, or milking; c: liner closing: and d: liner closed or rest. The duration of each phase is measured between the points at which the pulsation chamber vacuum is $4 \mathrm{kPa}$ below nominal system vacuum (a-to-b and b-to-c transitions) and 4 $\mathrm{kPa}$ above atmospheric pressure (d-to-a and c-to-d transitions).

Teat-end congestion can be reduced by adequate magnitude and duration of liner compression, primarily during the d-phase of pulsation (Williams et al., 1981). Liner compression facilitates venous flow and removal of interstitial fluid from teat-end tissues (IDF, 1987). Congestion of teat end tissues has been measured using a cutimeter (Hamann and Mein, 1988) and via ultrasonography (Neijenhuis et al., 2001; Gleeson et al., 2004). These studies have indicated that teat-end congestion occurs if the d-phase duration is too short. Moreover, too low a magnitude or duration of liner compression, or both, may fail to stimulate removal of mature keratin layers from the teat canal. Keratin loss during milking appears to be caused mainly by the application of liner compression via cyclic pulsation with the rate of milk flowing through the teat canal being a secondary factor (Lacy-Hulbert et al., 1996).

The International Organization for Standardization (ISO) specifies a minimum d-phase duration of $150 \mathrm{~ms}$ 
per pulsation cycle (ISO, 2007). The scientific basis for this recommendation is unclear due to a lack of resolution of d-phase durations applied in previous studies. A review of the literature carried out by Thompson (1973) indicated a trend toward increased udder health problems at high pulsation rate and wide pulsation ratio, concluding that d-phases shorter than some minimum limit from somewhere between 140 to $600 \mathrm{~ms}$ tended to cause injury to teats. Previous authors have highlighted the importance of d-phase duration in preventing new mastitis infections (O'Shea et al., 1984), controlling bulk milk SCC (Osterås et al., 1995), and its influence on flow rate of milk extracted per pulsation cycle (Williams et al., 1981). Hamann and Mein (1996) concluded that a d-phase duration of at least $150 \mathrm{~ms}$ was enough to relieve congestion and that greater d-phase durations resulted in little further decrease in congestion or increase in milk flow (MF) rate, but they applied very few d-phase duration treatments in their study. The details of these relevant references are highlighted further in the discussion.

Bade et al. (2009) examined the effect of residual vacuum for massage (RVM; as an indicator of liner compression), milking vacuum level and b-phase duration on MF. The duration of the d-phase of pulsation was held constant at $220 \mathrm{~ms}$ in these studies. When changing RVM from 16 to $30 \mathrm{kPa}, \mathrm{MF}$ increased by about $0.2 \mathrm{~kg} / \mathrm{min}$ at a milking system vacuum of 42 $\mathrm{kPa}$, whereas at a milking system vacuum level of 53 $\mathrm{kPa}$, the effect of the same increase in RVM was approximately 3 times greater, or $0.6 \mathrm{~kg} / \mathrm{min}$. This suggests that a greater degree of teat tissue congestion occurred at a higher milking vacuum level, as the effect of increased liner compression and resulting congestive relief was more pronounced at the higher vacuum level. Extending b-phase duration had much less influence on the development of teat tissue congestion during one pulsation cycle than did increasing the vacuum.

The objective of the present study was to analyze the effect of the duration of the d-phase of pulsation on the cross-sectional area of the teat canal (CA) during the period of peak milk flow rate (PMF) from bovine teats. A secondary objective was to test if the effect of d-phase duration on teat canal cross-sectional area was influenced by milking system vacuum level, milking phase (b-phase) duration, and liner overpressure.

\section{MATERIALS AND METHODS}

A quarter milking analyses device (Mi4), designed and built at the Milking Research and Instruction Laboratory at the University of Wisconsin-Madison, was used to implement the experimental treatments
(Table 1). The Mi4 is a high-precision, portable data collection device capable of applying various combinations of vacuum and pulsator settings during milking. In addition to precise continuous measurement of milk yield (and thus flow rate) at the quarter level, the Mi4 is equipped with vacuum transducers in the short milk tube, mouthpiece chamber, and pulsation chamber of each teat cup. A custom Labview (National Instruments, Austin, TX) front panel facilitated establishing user defined levels of system vacuum and individual quarter pulsator on and off times along with custom data logging frequencies and treatment interval periods. This quarter milking device ensures that one quarter is not influenced by the MF rates from the other quarters. Simultaneous pulsation was used in this experiment, however, because each quarter is milked individually, this will not influence the results. The pulsator on and off times describe the timing of the solenoid on the pulsator. Detailed pulsation system characteristics (i.e., a-, b-, c-, and d-phases, rate and ratio) for each experimental treatment are detailed in Table 1.

\section{Cow Selection and Experimental Design}

The Mi4 was used to milk 18 cows on the day before the experiment with treatment D175 (see Table 1 for detailed settings). This setting was also used to milk cows on evening milkings following each experimental treatment day. Cows were chosen for the experiment that had a PMF period (defined as being within $80 \%$ of the maximum MF) of at least $60 \mathrm{~s}$. Cows with less than 3 suitable quarters were dropped from the selection process. After these processing steps, 8 cows were dropped, leaving 10 cows in the final analysis. The minimum, mean, maximum, and standard deviation values for each quarter and for each cow was computed using the PROC MEANS procedure in SAS (SAS Institute Inc., 2015 ). The cows used had a mean parity of 2.1 (range 1-5) with mean days in milk of 295 (range $72-366$ ). A data sampling frequency of $1,000 \mathrm{~Hz}$ was used for all milk weight and vacuum data. The Mi4 device was located in the parlor pit. Vacuum was sourced from the milking machine's main milk line, which supplied the regulator and pulsator systems of the Mi4. All teats were stripped, cleaned, predipped, and wiped before application of the teat cups. Attachment of the teat cups occurred approximately 60 to $90 \mathrm{~s}$ after the initiation of premilking preparation procedures as recommended by Rasmussen et al. (1992).

It was postulated that teat length might influence the results, especially if the teat was too short to enter the zone of collapse of the liner. Therefore, teat length was taken on the last day of the experiment post cleaning and stripping and before teat cup attachment. 


\section{Experiment 1, Effect of Time on Treatment}

A pilot study was designed to determine if the duration of the applied treatment has a significant effect on the teat canal area. The cows were milked with the Mi4 using treatments D50 (pulsation on time of 575 $\mathrm{ms}$, pulsation off time of $125 \mathrm{~ms}$, system vacuum of 40 $\mathrm{kPa}$ ), D175 (pulsation on time of $575 \mathrm{~ms}$, pulsation off time of $250 \mathrm{~ms}$, system vacuum of $40 \mathrm{kPa}$ ), and D300 (pulsation on time of $575 \mathrm{~ms}$, pulsation off time of 375 ms, system vacuum of $40 \mathrm{kPa}$; Table 1). Milking began with D175, followed by either D300 or D50, and then returning to D175. These treatments were applied for 30 s each. The order of D300 and D50 was assigned to cows randomly before beginning the experiment. A liner with over pressure $(\mathbf{O P})$ of $9.8 \mathrm{kPa}$ was used. The $\mathrm{OP}$ is the vacuum in the pulsation chamber at the point where milk begins to flow from the teat during the aphase of pulsation (Leonardi et al., 2015). The exact a-, b-, c-, and d-phases of pulsation for each treatment combination were measured in a dry pulsation test using the AlfaTronic Tester MkV pulsation analyzer (De Laval, Tumba, Sweden). The first 3 pulsation cycles of each treatment were deleted from analysis to allow treatment conditions to stabilize and reduce any potential carryover effect from previous treatments. The MF was computed by linear regression of milk weight over time for the remaining within-treatment pulsation cycles. The PMF period was identified for each quarter and data from the low flow period was not used in the analysis. Milk ratio (MR, i.e., the time that milk is flowing divided by the full pulsation cycle time) and short milk tube vacuum $\left(\mathbf{V}_{\text {SMT }}\right)$ was calculated for each pulsation cycle using the pulsation chamber vacuum data, with liner OP values from Leonardi et al. (2015), marking the transition between milking and rest phases.

\section{Experiment 2, d-Phase Duration}

The pulsator off time was manipulated to achieve d-phase duration treatments of approximately 50, 100, $150,175,200,250$, and $300 \mathrm{~ms}$. Each treatment had a minimum duration of $8 \mathrm{~s}$ and consisted of an integer number of pulsation cycles. These d-phase treatments were applied in a randomized sequence, which varied from cow to cow for about $8 \mathrm{~s}$ each, with a control treatment of $175 \mathrm{~ms}$ d-phase repeated after every treatment to control for carryover effects between treat-

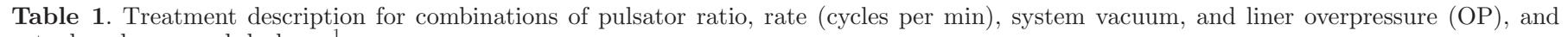
actual a-, b-, c-, and d-phases ${ }^{1}$

\begin{tabular}{|c|c|c|c|c|c|c|c|c|c|c|c|}
\hline Day & Treatment & $\begin{array}{c}\text { P. On } \\
(\mathrm{ms})\end{array}$ & $\begin{array}{l}\text { P. Off } \\
(\mathrm{ms})\end{array}$ & $\begin{array}{c}\text { Ratio } \\
(\%)\end{array}$ & $\begin{array}{c}\text { Rate } \\
\text { (c/min) }\end{array}$ & $\begin{array}{l}\text { Vacuum } \\
(\mathrm{kPa})\end{array}$ & $\begin{array}{c}\mathrm{OP} \\
(\mathrm{kPa})\end{array}$ & $\begin{array}{c}\text { a-phase } \\
\text { (ms) }\end{array}$ & $\begin{array}{l}\text { b-phase } \\
\text { (ms) }\end{array}$ & $\begin{array}{c}\text { c-phase } \\
\text { (ms) }\end{array}$ & $\begin{array}{c}\text { d-phase } \\
\text { (ms) }\end{array}$ \\
\hline 1 & D50 & 575 & 125 & 0.82 & 85.7 & 40 & 9.8 & 90 & 470 & 88 & 54 \\
\hline 1 & D100 & 575 & 175 & 0.77 & 80.0 & 40 & 9.8 & 90 & 471 & 87 & 106 \\
\hline 1 & D150 & 575 & 225 & 0.72 & 75.0 & 40 & 9.8 & 89 & 471 & 88 & 154 \\
\hline 1 & D175 & 575 & 250 & 0.70 & 72.7 & 40 & 9.8 & 88 & 471 & 86 & 182 \\
\hline 1 & D200 & 575 & 275 & 0.68 & 70.6 & 40 & 9.8 & 89 & 470 & 87 & 208 \\
\hline 1 & D250 & 575 & 325 & 0.64 & 66.7 & 40 & 9.8 & 89 & 469 & 88 & 257 \\
\hline 1 & D300 & 575 & 375 & 0.61 & 63.2 & 40 & 9.8 & 90 & 468 & 87 & 307 \\
\hline 2 & DB50 & 775 & 125 & 0.86 & 66.7 & 40 & 9.8 & 92 & 668 & 89 & 53 \\
\hline 2 & DB100 & 775 & 175 & 0.82 & 63.2 & 40 & 9.8 & 92 & 670 & 88 & 103 \\
\hline 2 & DB150 & 775 & 225 & 0.78 & 60.0 & 40 & 9.8 & 90 & 670 & 88 & 154 \\
\hline 2 & DB175 & 775 & 250 & 0.76 & 58.5 & 40 & 9.8 & 90 & 671 & 88 & 179 \\
\hline 2 & DB200 & 775 & 275 & 0.74 & 57.1 & 40 & 9.8 & 92 & 668 & 88 & 204 \\
\hline 2 & DB250 & 775 & 325 & 0.70 & 54.5 & 40 & 9.8 & 90 & 672 & 88 & 255 \\
\hline 2 & DB300 & 775 & 375 & 0.67 & 52.2 & 40 & 9.8 & 90 & 670 & 86 & 307 \\
\hline 3 & DV50 & 575 & 125 & 0.82 & 85.7 & 50 & 9.8 & 95 & 465 & 90 & 53 \\
\hline 3 & DV100 & 575 & 175 & 0.77 & 80.0 & 50 & 9.8 & 92 & 467 & 91 & 102 \\
\hline 3 & DV150 & 575 & 225 & 0.72 & 75.0 & 50 & 9.8 & 92 & 469 & 90 & 152 \\
\hline 3 & DV175 & 575 & 250 & 0.70 & 72.7 & 50 & 9.8 & 90 & 470 & 89 & 178 \\
\hline 3 & DV200 & 575 & 275 & 0.68 & 70.6 & 50 & 9.8 & 90 & 472 & 90 & 204 \\
\hline 3 & DV250 & 575 & 325 & 0.64 & 66.7 & 50 & 9.8 & 90 & 470 & 91 & 252 \\
\hline 3 & DV300 & 575 & 375 & 0.61 & 63.2 & 50 & 9.8 & 90 & 467 & 91 & 305 \\
\hline 4 & DC50 & 575 & 125 & 0.82 & 85.7 & 40 & 18 & 98 & 467 & 95 & 42 \\
\hline 4 & DC100 & 575 & 175 & 0.77 & 80.0 & 40 & 18 & 98 & 465 & 95 & 94 \\
\hline 4 & DC150 & 575 & 225 & 0.72 & 75.0 & 40 & 18 & 97 & 467 & 95 & 143 \\
\hline 4 & DC175 & 575 & 250 & 0.70 & 72.7 & 40 & 18 & 95 & 468 & 93 & 172 \\
\hline 4 & DC200 & 575 & 275 & 0.68 & 70.6 & 40 & 18 & 95 & 469 & 93 & 195 \\
\hline 4 & DC250 & 575 & 325 & 0.64 & 66.7 & 40 & 18 & 98 & 462 & 96 & 245 \\
\hline 4 & DC300 & 575 & 375 & 0.61 & 63.2 & 40 & 18 & 98 & 462 & 94 & 298 \\
\hline
\end{tabular}

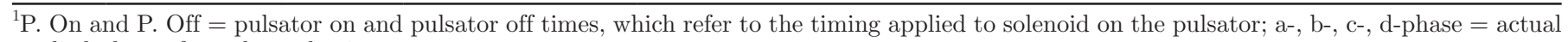
applied phases from dry pulsation tests. 
ments. The choice of treatment application duration of $8 \mathrm{~s}$ was made to ensure that at least one entire sequence of treatments was applied to each cow. The $7 \mathrm{~d}$-phase durations were applied at 2 vacuum levels (40 and 50 $\mathrm{kPa}$ ), 2 pulsator on times (575 and $775 \mathrm{~ms}$ ), and 2 levels of liner OP (9.8 and $18 \mathrm{kPa}$ ), over the course of 4 $\mathrm{d}$ as described in Table 1. The data were collected and processed as described above.

\section{Estimating Teat Canal Cross-Sectional Area}

Swelling of the teat tissue surrounding the canal will act to decrease CA during the milking phase of pulsation. Liner compression during the d-phase of pulsation acts to increase CA during the subsequent milking phase of pulsation by reducing congestion (Reinemann et al., 2008). Furthermore, Williams et al. (1981) showed that the MF rate profile from a teat changes within one pulsation cycle when a change in compressive load is applied. The CA can be determined from MF rate using the following equation:

$$
\mathrm{CA}=\alpha \times \mathrm{Q} \times \mathrm{MR}^{-1} \times\left(\mathrm{V}_{\mathrm{SMTb}}+4,500\right)^{-1 / 2},
$$

where $\alpha$ is a constant for an individual teat canal and is estimated as $28.4\left(\mathrm{~kg} / \mathrm{m}^{3}\right)^{1 / 2}, \mathrm{~V}_{\mathrm{SMTb}}$ is the vacuum in the short milk tube $(\mathrm{Pa})$ during the milking phase, $\mathrm{Q}$ is the volumetric flow rate $\left(\mathrm{m}^{3} / \mathrm{s}\right)$ of milk from the teat, and MR is the milk ratio (i.e., the fraction of the pulsation cycle during which milk is flowing). For a detailed derivation of equation [1], see Appendix.

\section{Statistical Analysis}

Experiment 1. The following mixed model procedure (Proc Mixed; SAS Institute Inc., 2015) was used to assess if CA changed within the 30 -s treatment periods.

$$
\mathrm{CA}=\mathrm{TL}+\text { Treatment }+ \text { Time }+ \text { Treatment } \times \text { Time, }
$$

where Treatment (d-phase duration) was chosen as a class variable; and TL (teat length) and Time (elapsed time since the beginning of each treatment) were chosen as continuous variables. Cow and Quarter were declared as class variables with Quarter within cow declared as a random variable and a repeated measure with auto regressive covariance structure, $\mathrm{AR}(1)$.

Experiment 2. A mixed model procedure (Proc Mixed; SAS Institute Inc., 2015) was used to analyze the effect of the treatments on CA as follows:

$$
\mathrm{CA}=\mathrm{TL}+\text { Day }+ \text { Treatment }+ \text { Day } \times \text { Treatment, }[3]
$$

where TL $=$ teat length covariate, Day $=$ day (vacuum level, b-phase duration, and liner OP), and Treatment $=\mathrm{d}$-phase duration. Day, treatment, quarter and cow were declared as class variables. Cow, Quarter nested within cow, and interactions treatment $\times$ quarter and day $\times$ quarter were defined as random variables. Quarter nested within cow was defined as a repeated measure. The data satisfied the criteria for independent observations according to a chi-square test; therefore, the compound symmetry covariance structure was used. The SAS macro \%PDMIX800 was used to assign letters designating significance to the model outputs (Saxton, 1998). The interactive term in equation [3] was the least significant term $(P=0.5)$ and was removed from the model first. Teat length was also not significant $(P$ $=0.06)$ and was removed, yielding the final model:

$$
\mathrm{CA}=\text { Day }+ \text { Treatment. }
$$

\section{RESULTS}

\section{Experiment 1: Effect of Time on Treatment}

The TL was the least significant term $(P=0.2)$ and was removed from the model. Mean teat length was $47 \mathrm{~mm}$ (range 40-66 $\mathrm{mm}$ ). The main effect of treatment (d-phase duration) on CA was highly significant $(P<0.001)$, whereas the interactive term treatment $\times$ time interaction was not significant $(P=0.10)$ in the reduced model. A third iteration with the interactive term removed showed that treatment remained significant $(P=0.04)$ and the effect of time on each of the 3 -d phase treatments was not significant (Table 2 ). The effect of time on D50 was not significant $(P=0.59)$, the effect of time on D175 was not significant $(P=0.35)$, and the effect of time on D300 was not significant $(P$ $=0.49)$.

\section{Experiment 2}

Effect of d-Phase Duration on CA. The main effect of d-phase duration on CA was highly significant

Table 2. Effect time on canal area for 3 treatments of experiment 1

\begin{tabular}{lccc}
\hline d-phase & $\begin{array}{c}\mathrm{CA}^{1} \text { estimate } \\
\left(\mathrm{mm}^{2}\right)\end{array}$ & $\begin{array}{c}\text { Time effect } \\
\left(\mathrm{mm}^{2} \text { per } \mathrm{s}\right)\end{array}$ & $P$-value \\
\hline 50 & 3.44 & -0.002 & 0.59 \\
175 & 3.32 & 0.003 & 0.35 \\
300 & 3.60 & 0.005 & 0.49 \\
\hline
\end{tabular}

${ }^{1} \mathrm{CA}=$ canal area. 
Table 3. Effect of d-phase duration on canal area across experimental days of experiment 2

\begin{tabular}{lcccc}
\hline $\begin{array}{l}\text { d-phase } \\
(\mathrm{ms})\end{array}$ & $\begin{array}{c}\text { Canal area } \\
\left(\mathrm{mm}^{2}\right)\end{array}$ & $\mathrm{SE}$ & $\begin{array}{c}\text { Letter } \\
\text { group }\end{array}$ & $\begin{array}{c}\text { Change from } \\
\text { control 175 } \mathrm{ms}^{2} \\
(\%)\end{array}$ \\
\hline 300 & 3.21 & 0.27 & $\mathrm{~A}$ & 1.5 \\
250 & 3.20 & 0.27 & $\mathrm{~A}$ & 1.0 \\
200 & 3.21 & 0.27 & $\mathrm{~A}$ & 1.5 \\
175 & 3.18 & 0.26 & $\mathrm{~A}$ & 0.5 \\
150 & 3.17 & 0.26 & $\mathrm{~A}$ & -2.3 \\
100 & 3.09 & 0.27 & $\mathrm{~B}$ & -3.1 \\
50 & 3.07 & 0.26 & $\mathrm{~B}$ & \\
\hline
\end{tabular}

${ }^{1} \mathrm{~d}$-phases with different letter groups differ significantly $(P<0.05)$.

${ }^{2}$ Percentage difference in canal area from the control treatment, which had a d-phase of $175 \mathrm{~ms}$.

$(P<0.001)$. The estimates of $\mathrm{CA}$ for each of the 7 d-phase durations are presented in Table 3. The CA of the 100 and $50 \mathrm{~ms}$ d-phase durations were significantly different $(P<0.05)$ than $\mathrm{CA}$ of the 5 other d-phase durations. The CA of the $100 \mathrm{~ms}$ d-phase duration was $2.3 \%$ smaller than the control treatment of $175 \mathrm{~ms}$ dphase duration and the reduction was $3.1 \%$ for the 50 ms d-phase duration treatment (Table 3).

Effect of b-Phase Duration, Vacuum Level, and Liner $\boldsymbol{O P}$ on $\boldsymbol{C A}$. The main effect of day on CA was highly significant $(P<0.001)$. The lack of significance of the (day $\times$ d-phase) interaction indicates that the effect of d-phase duration was not different for the long b-phase, high vacuum, or high liner OP conditions. The estimates of $\mathrm{CA}$ for each of the $4 \mathrm{~d}$ are presented in Table 4. The mean CA of the high OP condition (d 4) was $10 \%$ greater than the control condition and significantly greater than all other days $(P<0.0001)$. This indicates that increasing liner OP (higher compression liner) reduced teat-end congestion across all d-phase durations. The mean CA for the long milking phase duration condition (d 2) was $8 \%$ lower than the control condition and significantly lower than the CA on the high OP treatment (d 4). The $3 \%$ change in $\mathrm{CA}$ in the high vacuum condition (d 3) was not significantly different from the control condition, indicating that increasing the milking vacuum level did not produce a significant change in teat-end congestion in this study.

\section{DISCUSSION}

The change in CA with time over a 30-s treatment period was tested for 50, 175, and $300 \mathrm{~ms}$ d-phase durations. The slope of CA over time was not significant. This implies that the effect of a treatment on CA becomes evident within a few pulsation cycles. The concept that the effects of changes in milking conditions materialize rapidly is supported by Williams et al. (1981) who noted that if the compressive load applied by the liner changes, the flow-rate profiles change in the next pulsation cycle. Nonetheless, we have accounted for the effect of time on CA by applying our treatments in a randomized fashion during the PMF period from cow to cow. These results add confidence in our experimental equipment and methods to further explore effects of pulsation, vacuum, and liner conditions on MF and thereby $\mathrm{CA}$ and teat congestion in short duration experiments. Applying multiple treatments to individual quarters during a single milking eliminates other sources of error. Table 3 illustrates that differences of $2 \%$ change in CA were detected as statistically different.

Our results revealed a significant reduction in CA with d-phase durations of 100 and $50 \mathrm{~ms}$ and when

Table 4. Effect of day on canal area across all d-phase durations

\begin{tabular}{|c|c|c|c|c|c|c|}
\hline Day & $\begin{array}{c}\text { P. On }{ }^{1} \\
(\mathrm{~ms})\end{array}$ & $\begin{array}{c}\text { Vacuum } \\
(\mathrm{kPa})\end{array}$ & $\mathrm{OP}(\mathrm{kPa})$ & $\begin{array}{c}\text { Canal area } \\
\left(\mathrm{mm}^{2}\right)\end{array}$ & SE & $\begin{array}{l}\text { Letter } \\
\text { group }{ }^{2}\end{array}$ \\
\hline 1: Control & 575 & 40 & 9.8 & 3.16 & 0.27 & B \\
\hline 2: Long b-phase & 775 & 40 & 9.8 & 2.91 & 0.27 & $\mathrm{C}$ \\
\hline 3: High vacuum & 575 & 50 & 9.8 & 3.06 & 0.27 & $\mathrm{BC}$ \\
\hline 4: High $\mathrm{OP}^{3}$ & 575 & 40 & 18 & 3.51 & 0.27 & A \\
\hline
\end{tabular}


compared with d-phase durations of $150,175,225,250$, and $300 \mathrm{~ms}$ (Table 3). These results support the ISO specified minimum $150 \mathrm{~ms}$ d-phase duration.

A challenge experiment by O'Shea et al. (1984), in which 30 cows were milked on a half udder basis for $100 \mathrm{~d}$, tested 2 levels of d-phase duration (72 and 187 ms) for their effect on new mastitis infections when the teats were dipped in a Staphylococcus aureus culture before and after milking. The short d-phase duration resulted in one new infection every 800 quarter milkings, whereas the long d-phase resulted in one new infection every 4,000 quarter milkings. Presumably the teats on the short d-phase treatment became more congested that those on the longer $\mathrm{d}$-phase treatment making them more susceptible to new mastitis infections. The main difference between our experiment and that of O'Shea et al. (1984) was that they maintained a constant pulsation rate, resulting in a longer b-phase on the short d-phase treatment, whereas we controlled both pulsation rate and pulsation ratio, in the interest of isolating the d-phase effect. However, this should not prevent comparisons of results to be drawn because we did not find significant interactions between the effect of d-phase durations and b-phase durations, vacuum levels, or liner OP.

Another challenge experiment carried out by Reitsma et al. (1981) found that the occurrence of new quarter infections increased considerably with a decrease in duration of liner closure (liner more than half closed). Rear quarters were also infected more readily than front quarters. It is not easy to align the results of our study with those of Reitsma et al., because the pulsation system characteristics are not presented as a-, b-, c-, and d-phases. Moreover, our study focused on the PMF period rather that the entire milking, and used finer treatment graduations. However, in general our study and the study of Rietsma et al. conclude that a very short d-phase can have measureable negative effects.

A study by Williams et al. (1981) noted that the effect of increasing the duration of the collapse phase was to increase the duration of the high flow rate in the early part of the flow period (within each pulsation cycle), stating that the effect was relatively small when compared with varying the magnitude of the compressive load applied by the liner, provided that the d-phase was longer than $100 \mathrm{~ms}$. However, their next graduation was $500 \mathrm{~ms}$ in d-phase; hence, our study provides details of the finer graduations both below and above the critical level of $100 \mathrm{~ms}$ cited by Williams et al. (1981). Likewise, our results showed that increasing liner OP (and corresponding increase in compressive load) produced a change in CA, indicating that a high
OP liner is more effective than a lower OP liner at removing congestion.

An observational study by Osterås et al. (1995) found that a d-phase duration of less than $250 \mathrm{~ms}$ was associated with significant elevation in bulk milk SCC, a higher incidence of acute clinical mastitis and a higher frequency of cows having mastitis associated with major pathogens as compared with a d-phase of greater than $331 \mathrm{~ms}$. It is difficult to compare these results with those of our study because drawing recommendations about pulsation characteristics from associations between co-varying factors in an observational study is difficult. Moreover, no information was provided relating to herd management practices, housing conditions and management, cluster removal settings, or milking routines or hyperkeratosis status of the herds. We designed our study to isolate the effect of d-phase duration on teat end congestion and found that significant congestion develops below a d-phase duration of $150 \mathrm{~ms}$. No significant differences in CA were found between 150 and $300 \mathrm{~ms}$ during the PMF period in this study.

\section{CONCLUSIONS}

A significant reduction occurred in CA with d-phase durations of 100 and $50 \mathrm{~ms}$ when compared with dphase durations of $150,175,225,250$, and $300 \mathrm{~ms}$. These results support the ISO-specified minimum 150-ms d-phase duration. No significant interaction was found between the effect of d-phase duration and b-phase durations, vacuum levels, or liner OP, indicating that we found no basis for a benefit of increasing or altering d-phase durations for higher vacuum levels, longer b-phase durations, or lower liner compression.

\section{ACKNOWLEDGMENTS}

Financial support of the University of WisconsinMadison, Teagasc (Fermoy, Cork, Ireland), Avon Dairy Solutions (Melksham, UK), and Dairy Australia (Southbank, Victoria, Australia) are gratefully acknowledged. We acknowledge the assistance of the staff in the Dairy Cattle Centre at the University of Wisconsin-Madison. We acknowledge Peter Crump at the Statistical Consulting Group in the College of Agricultural and Life Sciences (CALS, Madison, WI) for statistical advice.

\section{REFERENCES}

Bade, R. D., D. J. Reinemann, M. Zucali, P. L. Ruegg, and P. D. Thompson. 2009. Interactions of vacuum, b-phase duration, and liner compression on milk flow rates in dairy cows. J. Dairy Sci. 92:913-921. 
Brown, G. 2002. The history of the Darcy-Weisbach equation for pipe flow resistance. Pages 34-43 in Environmental and Water Resources History. American Society of Civil Engineers, Reston, VA.

Bruckmaier, R. M., and J. W. Blum. 1996. Simultaneous recording of oxytocin release, milk ejection and milk flow during milking of dairy cows with and without prestimulation. J. Dairy Res. 63:201208.

Gleeson, D. E., E. J. O'Callaghan, and M. Rath. 2003. Effect of vacuum level on bovine teat-tissue and milking characteristics. Ir. J. Agric. Food Res. 42:205-211.

Gleeson, D. E., E. J. O'Callaghan, and M. V. Rath. 2004. Effect of liner design, pulsator setting, and vacuum level on bovine teat tissue changes and milking characteristics as measured by ultrasonography. Ir. Vet. J. 57:289-296.

Hamann, J., and G. A. Mein. 1988. Responses of the bovine teat to machine milking - Measurement of changes of thickness of the teat apex. J. Dairy Res. 55:331-338.

Hamann, J., and G. A. Mein. 1996. Teat thickness changes may provide biological test for effective pulsation. J. Dairy Res. 63:179-189.

IDF. 1987. Machine milking and mastitis. Bulletin no. 215. International Dairy Federation, Brussels, Belgium.

ISO. 2007. 5707: Milking machine installations-Construction and performance. International Organization for Standardization, Geneva, Switzerland.

Lacy-Hulbert, S. J., J. E. Hillerton, and M. W. Woolford. 1996. Influence of pulsationless milking on teat canal keratin growth and turnover. J. Dairy Res. 63:517-524.

Leonardi, S., J. F. Penry, F. M. Tangorra, P. D. Thompson, and D. J. Reinemann. 2015. Methods of estimating liner compression. J. Dairy Sci. 98:6905-6912.

Mein, G. A., D. M. Williams, and C. C. Thiel. 1987. Compressive load applied by the teatcup liner to the bovine teat. J. Dairy Res. 54:327-337.

Neijenhuis, F., G. H. Klungel, and H. Hogeveen. 2001. Recovery of cow teats after milking as determined by ultrasonographic scanning. J. Dairy Sci. 84:2599-2606.

O'Shea, J., E. O'Callaghan, and W. J. Meaney. 1984. Effect of machine milking on new mastitis infections. Isr. J. Agric. Res. 23:155-171.

Osterås, O., O. Ronningen, L. Sandvik, and S. Waage. 1995. Field studies show associations between pulsator characteristics and udder health. J. Dairy Res. 62:1-13.

Rasmussen, M. D., E. S. Frimer, D. M. Galton, and L. G. Petersson. 1992. The influence of premilking teat preparation and attachment delay on milk-yield and milking performance. J. Dairy Sci. 75:2131-2141.

Reinemann, D. J., R. Bade, M. Zucali, C. Spanu, and P. L. Ruegg 2008. Understanding the influence of machine milking on teat defence mechanisms. In IDF International Conference on Mastitis Control, IDF, The Hague, the Netherlands.

Reitsma, S. Y., E. J. Cant, R. J. Grindal, D. R. Westgarth, and A. J. Bramley. 1981. Effect of duration of teat cup liner closure per pulsation cycle on bovine mastitis. J. Dairy Sci. 64:2240-2245.

SAS Institute Inc. 2015. SAS 9.4. Statements: Reference, Fourth Edition. Accessed Aug. 5, 2015. http://support.sas.com/documentation/cdl/en/lestmtsref/68024/HTML/default/viewer.htm\#p00hx g3x8lwiven1f0e9axziw57y.htm.

Saxton, A. M. 1998. A macro for converting mean separation output to letter groupings in Proc Mixed. Pages 1243-1246 in Proc. 23rd SAS Users Group Int., SAS Institute, Cary, NC.

Thompson, P. D. 1973. The effect of pulsation ratio, vacuum level and flow rate on udder health. in National Dairy Housing Conference, Michigan State University, Feb. 6-8, 1973. American Society of Agricultural Engineers, St. Joseph, MI.

Williams, D. M., and G. A. Mein. 1986. The bovine teat canal-Information from measurement of velocity of milk flow from the teat. J. Dairy Res. 53:179-185.

Williams, D. M., G. A. Mein, and M. R. Brown. 1981. Biological responses of the bovine teat to milking-Information from measurements of milk flow-rate within single pulsation cycles. J. Dairy Res. 48:7-21.
Zecconi, A., J. Hamann, V. Bronzo, and G. Ruffo. 1992. Machineinduced teat tissue reactions and infection risk in a dairy herd free from contagious mastitis pathogens. J. Dairy Res. 59:265-271.

Zwertvaegher, I., S. De Vliegher, B. Verbist, A. Van Nuffel, J. Baert, and S. Van Weyenberg. 2013. Short communication: Associations between teat dimensions and milking-induced changes in teat dimensions and quarter milk somatic cell counts in dairy cows. J. Dairy Sci. 96:1075-1080.

\section{APPENDIX \\ Derivation of Teat Canal Cross-Sectional Area Formula}

The flow of milk through the teat canal was modeled as incompressible fluid flow through a tube accounting for frictional losses using the Darcy-Wiesback equation (Brown, 2002);

$$
\Delta \mathrm{p}=\mathrm{f}_{\mathrm{D}} \times \mathrm{L} / \mathrm{D} \times \rho / 2 \times \mathrm{u}^{2},
$$

where $\Delta \mathrm{p}=$ pressure difference across the tube $(\mathrm{Pa}), \mathrm{f}_{\mathrm{D}}$ $=$ Darcy friction factor (dimensionless), $\mathrm{L} / \mathrm{D}=$ length to diameter ratio of the tube (dimensionless), $\rho=$ fluid density $\left(\mathrm{kg} / \mathrm{m}^{3}\right)$, and $\mathrm{u}=$ fluid velocity $(\mathrm{m} / \mathrm{s})$.

In this case, $\Delta p$ is the pressure difference across the teat canal. A positive pressure in the udder cistern of 4,500 Pa was assumed based on a study by Bruckmaier and Blum (1996); therefore,

$$
\Delta \mathrm{p}=\left|\mathrm{V}_{\mathrm{SMTb}}\right|+4,500,
$$

where $\mathrm{V}_{\mathrm{SMTb}}$ is the vacuum in the short milk tube $(\mathrm{Pa})$ during the milking phase.

The $u$ was computed as

$$
\mathrm{u}=\mathrm{Q} / \mathrm{CA},
$$

where CA = canal area $\left(\mathrm{m}^{2}\right)$ and $\mathrm{Q}$ is the volumetric flow rate $\left(\mathrm{m}^{3} / \mathrm{s}\right)$, which is found using equation [8]:

$$
\mathrm{Q}=\frac{(\mathrm{MF} / 60)}{\rho},
$$

where MF is the milk flow rate $(\mathrm{kg} / \mathrm{min})$ and $\rho$ is the density of milk $\left(1,030 \mathrm{~kg} / \mathrm{m}^{3}\right)$. Therefore,

$$
\mathrm{CA}=\alpha \times \mathrm{Q} \times\left(\mathrm{V}_{\mathrm{SMTb}}+4,500\right)^{-1 / 2},
$$

where

$$
\alpha=\left(\rho / 2 \times f_{D} \times L / D\right)^{1 / 2} .
$$


The value of $\alpha$ is assumed to be constant for an individual teat canal and is estimated as $28.4\left(\mathrm{~kg} / \mathrm{m}^{3}\right)^{1 / 2}$.

The $\mathrm{L} / \mathrm{D}$ ratio can be computed with knowledge of the length of a typical teat canal, taken as $0.01 \mathrm{~m}$ from Gleeson et al. (2003), and using a teat canal diameter (D) of $2 \mathrm{~mm}$. The $\mathrm{f}_{\mathrm{D}}$ term (dimensionless) represents the Darcy friction factor and was found to be 0.31 using equation [5]. Williams and Mein (1986) found that the velocity of milk from the teat canal with a liner vacuum of $40 \mathrm{kPa}$ was $7.5 \mathrm{~m} / \mathrm{s}$. Hence, $\mathrm{f}_{\mathrm{D}}$ can be found by parameterizing equation [5] with $\mathrm{u}=7.5 \mathrm{~m} / \mathrm{s}$ and $\Delta \mathrm{P}=$ $44,500 \mathrm{~Pa}$ (i.e., $40,000+4,500$ as per equation [6]).
The right-hand side of equation [9] is multiplied by the MR, to account for the fraction of the pulsation cycle during which milk is flowing to yield the final predictive equation:

$$
\mathrm{CA}=\alpha \times \mathrm{Q} \times \mathrm{MR}^{-1} \times\left(\mathrm{V}_{\mathrm{SMTb}}+4,500\right)^{-1 / 2} .
$$

Liner OP values from Leonardi et al. (2015) were used to mark the transition between milking and rest phases. 